\title{
DIVERSIDADE GENÉTICA EM FAMÍLIAS DE MEIOS-IRMÃOS DE PINHÃO MANSO
}

Linda Brenna Ribeiro Araújo1; Antônio Moreira Barroso Neto²; Georjane de Melo Castro Gondim³; Kátia Regina Alves Pires ${ }^{4}$; Cândida Hermínia Campos de Magalhães Bertini ${ }^{5}$

${ }^{1}$ Mestranda do Programa de Pós-Graduação em Agronomia-Fitotecnia / Centro de Ciências Agrárias, Universidade Federal do Ceará. (lindabrenna@gmail.com)

2Doutorando do Programa de Pós-Graduação em Agronomia-Fitotecnia / Centro de Ciências Agrárias, Universidade Federal do Ceará.

${ }^{3}$ Engenheira Agrônoma / Centro de Ciências Agrárias, Universidade Federal do Ceará.

${ }^{4}$ Graduanda em Agronomia / Centro de Ciências Agrárias, Universidade Federal do Ceará.

${ }^{5}$ Professora Associada do Departamento de Fitotecnia / Centro de Ciências Agrárias, Universidade Federal do Ceará.

Recebido em: 08/04/2017 - Aprovado em: 10/06/2017 - Publicado em: 20/06/2017 DOI: 10.18677/EnciBio_2017A41

\section{RESUMO}

O pinhão manso é uma oleaginosa que tem ganhado destaque por seu potencial para a produção de biodiesel. Estudos vêm sendo realizados buscando o desenvolvimento de variedades de pinhão manso com boas características morfoagronômicas, no entanto a espécie ainda se encontra em processo de domesticação, principalmente por conta da baixa variabilidade genética observada. Assim, objetivou-se com esse estudo avaliar a diversidade genética de acessos de pinhão manso da coleção de germoplasma da Universidade Federal do Ceará (UFC) e de suas famílias de meios-irmãos, a fim de avaliar seu comportamento nas duas gerações e otimizar a utilização dos genótipos. Para isso realizaram-se análises de DNA utilizando marcadores moleculares ISSR. Através do método UPGMA foi gerada a matriz de dissimilaridade genética, utilizada na elaboração do dendrograma e no agrupamento dos indivíduos, que também foi realizado através do método de otimização de Tocher. Doze iniciadores geraram amplificação e nove foram polimórficos. Os métodos de agrupamento geraram dois grupos de composição similar. Houve aumento significativo da variabilidade genética nas famílias de meiosirmãos, que poderão ser selecionadas para recombinações como fonte de variabilidade.

PALAVRAS-CHAVE: ISSR. Jatropha curcas. Marcadores moleculares. 


\title{
GENETIC DIVERSITY IN HALF-SIB FAMILIES OF PHYSIC NUT
}

\begin{abstract}
The jatropha is an oleaginous that has gained prominence by its potential for biodiesel production. Studies have been carried out seeking the development of varieties of jatropha with good morphoagronomic characteristics, however the species is still in the process of domestication, mainly due to the low genetic variability observed. Thus, this study was carried out to evaluate the genetic diversity of Jatropha accessions from the germplasm collection of the Federal University of Ceará (UFC) and their half-sib families in order to evaluate their behavior in the two generations and to optimize the use of genotypes. For this, DNA analyzes were performed using molecular markers ISSR. Using the UPGMA method, the genetic dissimilarity matrix was generated, which was used to create the dendrogram and the clustering of the individuals. The clustering was also performed by the Tocher optimization method. Twelve primers generated amplification and nine were polymorphic. The clustering methods generated two groups of similar composition. There was a significant increase in genetic variability in half-sib families, which could be selected for recombination as a source of variability.
\end{abstract}

KEYWORDS: ISSR. Jatropha curcas. Molecular markers.

\section{INTRODUÇÃO}

Pesquisas vêm sendo desenvolvidas em todo o mundo na busca por fontes alternativas de combustíveis, visando a preservação ambiental e uma maior segurança energética (SILVA et al., 2017; REIS et al., 2015). Uma alternativa para esta demanda consiste no desenvolvimento de variedades produtivas, adaptadas e resistentes de espécies de plantas oleaginosas promissoras, como o pinhão manso (MARQUES \& FERRARI, 2008; DRUMOND et al., 2016).

O pinhão manso é um arbusto perene, membro da família Euphorbiaceae, reconhecido por seu potencial para a produção de biodiesel (VIRGENS et al. 2017). A espécie se destaca como uma cultura perene alternativa, sem a necessidade de replantio anual, além de não competir diretamente com culturas alimentares e apresentar boa adaptação a diferentes climas e solos (MÜLLER et al., 2015; DRUMOND et al., 2016).

Na região semiárida do Brasil a espécie ganha ainda mais destaque devido a sua boa tolerância à seca, rusticidade e exigência em insolação compatível com esse ambiente (SPINELLI et al., 2014; NUNES et al., 2016). Além disso, a utilização de pinhão manso na região pode auxiliar na distribuição de renda, inserindo na cadeia produtiva de biocombustíveis os agricultores familiares (DRUMOND et al., 2016).

Apesar de seu grande potencial produtivo, a espécie ainda se encontra em fase de domesticação, assim, não existem sistemas de cultivo válidos para as regiões produtoras do Brasil ou mesmo cultivares desenvolvidos (LAVIOLA et al., 2014). Os programas de melhoramento de pinhão manso ainda estão em fase inicial e levando em consideração que o sucesso desses programas tem relação direta com a variabilidade genética disponível, faz-se necessária a avaliação da diversidade dos genótipos selecionados (REIS et al., 2015; ROCHA et al., 2016). A falta de informação sobre a variabilidade da espécie constitui um fator limitante para o cultivo do pinhão manso em muitos países, como o Brasil, pois esse conhecimento é 
fundamental para o desenvolvimento de genótipos mais produtivos (GRATIVOL et al. 2011).

A determinação da variabilidade genética dos acessos disponíveis para utilização no melhoramento é crucial (MAVUSO et al., 2016). Sua avaliação é realizada principalmente através de caracteres morfológicos e moleculares, com destaque para os últimos por sua capacidade de avaliar o genoma dos indivíduos sem influência ambiental. Através de marcadores moleculares ISSR (Inter Simple Sequence Repeats) é possível fazer estimativas da dissimilaridade entre os acessos, que constituem medidas de grande importância no estudo da divergência genética (JUHÁSZ et al., 2013).

Embora seja uma espécie alógama, estudos vêm evidenciando a baixa diversidade genética do pinhão manso no país (LAVIOLA et al., 2010). Assim, famílias de meios-irmãos vêm sendo estudadas como alternativa para aumentar a diversidade genética e possibilitar maiores ganhos por seleção (LAVIOLA et al., 2010; SPINELLI et al., 2014).

O conceito de famílias de meios-irmãos corresponde a indivíduos provenientes da mesma planta-mãe mas de doadores de pólen distintos. As avaliações dessas famílias e a estimativa de sua diversidade genética pode ser utilizada para estimar o potencial genético dos indivíduos e auxiliar na seleção dos melhores cruzamentos (RESENDE, 1991). Assim, objetivou-se com este trabalho avaliar a diversidade genética de genitores de pinhão manso selecionados da coleção de germoplasma da Universidade Federal do Ceará (UFC) e de suas famílias de meios-irmãos através de marcadores ISSR.

\section{MATERIAL E MÉTODOS}

O material vegetal constou de trinta e nove genótipos de pinhão manso provenientes da Coleção de Germoplasma da Universidade Federal do Ceará. Dentre os genótipos, dez correspondem aos acessos que apresentaram desempenho produtivo superior e menor porte da coleção quando avaliados em ensaio na região semiárida, e vinte e nove genótipos correspondem às suas famílias de meios irmãos, conforme mostra o Quadro 1.

QUADRO 1: Identificação, nome do acesso e origem dos 29 genótipos de pinhão manso avaliados.

\begin{tabular}{llll}
\hline & Identificação & Acesso & Origem \\
\hline Genitores & P1 & JCCE 034 & Crateús - CE \\
& P2 & JCCE 035 & Crateús - CE \\
& P3 & JCCE 038 & Crateús - CE \\
& P4 & JCCE 064 & Parambu - CE \\
& P5 & JCCE 053 & Parambu - CE \\
& P6 & JCCE 055 & Parambu - CE \\
& P7 & JCCE 014 & Quixadá - CE \\
& P8 & UFRRJFMI 002 & Rio de Janeiro - RJ \\
& P9 & UFRRJFMI 346 & Rio de Janeiro - RJ \\
& P10 & UFRRJFMI 874 & Rio de Janeiro - RJ \\
\hline Meios-Irmãos & M1 & 9-B3-L2 & Pentecoste - CE \\
& M2 & 9-B3-L1 & Pentecoste - CE \\
& M3 & 5-B2-L4 & Pentecoste - CE \\
& M4 & 4-B3-L3 & Pentecoste - CE \\
\hline
\end{tabular}




\begin{tabular}{lll}
\hline M5 & 1-B1-L4 & Pentecoste - CE \\
M6 & 1-B1-L3 & Pentecoste - CE \\
M7 & 10-B1-L1 & Pentecoste - CE \\
M8 & 8-B1-L3 & Pentecoste - CE \\
M9 & 6-B3-L3 & Pentecoste - CE \\
M10 & 6-B3-L4 & Pentecoste - CE \\
M11 & 1-B3-L4 & Pentecoste - CE \\
M12 & 10-B3-L1 & Pentecoste - CE \\
M13 & 3-B3-L4 & Pentecoste - CE \\
M14 & 3-B1-L4 & Pentecoste - CE \\
M15 & 2-B2-L6 & Pentecoste - CE \\
M16 & 2-B1-L3 & Pentecoste - CE \\
M17 & 3-B2-L1 & Pentecoste - CE \\
M18 & 8-B2-L7 & Pentecoste - CE \\
M19 & 8-B3-L1 & Pentecoste - CE \\
M20 & 6-B2-L8 & Pentecoste - CE \\
M21 & 5-B3-L1 & Pentecoste - CE \\
M22 & 5-B1-L3 & Pentecoste - CE \\
M23 & 4-B2-L6 & Pentecoste - CE \\
M24 & 4-B2-L5 & Pentecoste - CE \\
M25 & 7-B1-L3 & Pentecoste - CE \\
M26 & 7-B2-L8 & Pentecoste - CE \\
M27 & 2-B3-L2 & Pentecoste - CE \\
M28 & 9-B2-L6 & Pentecoste - CE \\
M29 & 10-B2-L8 & Pentecoste - CE \\
\hline
\end{tabular}

A extração de DNA foi realizada com base no protocolo descrito por DOYLE \& DOYLE (1990), utilizando-se folhas jovens dos genótipos. Foi realizado o teste de qualidade dos DNAs extraídos através de corrida em gel de agarose 0,8\%, verificando-se a presença e nitidez das bandas. As amostras aprovadas nos testes iniciais de qualidade foram quantificadas em espectrofotômetro NanoDrop 2000, onde também foi avaliada a relação das absorbâncias $A_{260} / A_{280}$, cujo valor ideal foi padronizado como o intervalo de 1,8 a 2,0. As amostras que não apresentaram qualidade nos testes foram extraídas novamente até a obtenção dos níveis desejados e posteriormente, foram diluídas até a concentração de $10 \mathrm{ng} / \mathrm{\mu L}$ e armazenadas a $-20 \stackrel{\circ}{\circ}$.

Foram realizados testes preliminares em três amostras de DNA escolhidas de forma aleatória com vinte e três iniciadores (Integrated DNA Technologies) ISSR com diferentes concentrações de $\mathrm{MgCl}_{2}(1,5 \mathrm{mM}, 2 \mathrm{mM}$ e 2,5 mM) e temperaturas de anelamento $\left(50{ }^{\circ} \mathrm{C}, 53^{\circ} \stackrel{\circ}{ } \mathrm{C}\right.$ e $\left.55^{\circ} \stackrel{\circ}{ } \mathrm{C}\right)$ a fim de otimizar as reações. Foram selecionadas: as temperaturas, concentrações e iniciadores que apresentaram amplificação de fragmentos de alta intensidade.

As reações de PCR (Polymerase Chain Reaction) apresentaram volume final de $25 \mu \mathrm{L}$ e utilizaram dNTPs $(0,2 \mathrm{mM}$ de cada), PCR Buffer (1x), iniciador $(0,8 \mu \mathrm{M})$, $\mathrm{MgCl}_{2}(2 \mathrm{mM})$, DNA genômico ( $30 \mathrm{ng} / \mu \mathrm{L}$ ) e Taq DNA polimerase (1 unidade). O ciclo do termociclador Axygen modelo THERM-1000 constou de 1 minuto de desnaturação a $94{ }^{\circ} \mathrm{C}, 30$ segundos de anelamento a $50 \stackrel{\circ}{\circ}$, $53{ }^{\circ} \mathrm{C}$ ou $55^{\circ} \mathrm{C}$ e 1 minuto de extensão a $72{ }^{\circ} \mathrm{C}$. O programa constou de 40 ciclos, havendo ainda 1 minuto de desnaturação inicial a $94{ }^{\circ} \mathrm{C}$ e 10 minutos de extensão final a $72{ }^{\circ} \mathrm{C}$, seguida de redução para $4{ }^{\circ} \mathrm{C}$. 
Os produtos da PCR foram submetidos à eletroforese em gel de agarose $2 \%$, preparado com tampão TBE $0,5 \mathrm{X}$. As eletroforeses foram realizadas a 90 Volts em cuba horizontal e o tempo médio de corrida foi de 1 hora e meia. Os géis foram corados com brometo de etídio $(10 \mathrm{mg} / \mathrm{mL})$ e suas imagens capturadas em fotodocumentador.

As imagens dos géis foram analisadas de forma a gerar uma matriz binária em que o número um foi utilizado para representar a presença de bandas e o zero a ausência. Foram criadas planilhas para todos os genótipos analisados e para cada iniciador que conferiu amplificação. O software GENES (CRUZ, 2008) foi utilizado para a realização das análises estatísticas. A matriz de dissimilaridade genética foi calculada aos pares entre os indivíduos utilizando o complemento do índice de similaridade de Jaccard:

$$
\mathrm{D}_{i j}=1-\frac{\mathrm{a}}{\mathrm{a}+\mathrm{b}+\mathrm{c}}
$$

Em que:

$\mathrm{a}=$ presença de bandas nos indivíduos i e j;

$\mathrm{b}=$ presença de bandas no indivíduo i e ausência no indivíduo j;

$\mathrm{C}=$ ausência de banda no indivíduo i e presença no indivíduo j;

A partir da matriz de dissimilaridade gerada realizou-se o agrupamento dos genótipos segundo o método de otimização de Tocher. $O$ dendrograma foi construído utilizando o algoritmo UPGMA (Unweighted Pair Group Method using Arithmetic averages) e foi calculado seu coeficiente de correlação cofenético (r). O ponto de corte para a separação dos genótipos foi definido com base na estimativa da dissimilaridade genética média (Dgm):

$$
\mathrm{D}_{\mathrm{gm}}=\frac{\sum \mathrm{D}_{\mathrm{gij}}}{\mathrm{N}}
$$

Em que:

Dgij = dissimilaridade genética entre os indivíduos i e j;

$\mathrm{N}$ = número de pares obtidos.

Considerando duas populações distintas, calculou-se a heterozigose média para os locus avaliados dos genitores e das famílias de meios-irmãos. Foi calculado também o Conteúdo de Informação Polimórfica (PIC) para cada iniciador conforme a expressão:

$$
P I C=1-\sum_{j}^{n}=P_{i j}^{2}
$$

Em que:

$$
P_{i j}=\text { frequência do alelo } j \text { no marcador } i \text {. }
$$

\section{RESULTADOS E DISCUSSÃO}

Como resultados dos testes preliminares de PCR, verificou-se que dos 23 iniciadores testados apenas 12 amplificaram, os quais foram utilizados em novas reações com todos os genótipos estudados. Como resultado das avaliações dos géis de eletroforese, verificou-se que 9 iniciadores haviam amplificado bandas polimórficas (Tabela 1). 
TABELA 1: Identificação dos iniciadores ISSR polimórficos, sequência $5^{\prime} \rightarrow 3^{\prime}$, temperatura de anelamento e conteúdo de informação polimórfica (PIC).

\begin{tabular}{cccc}
\hline Iniciador & Sequência 5' $\rightarrow \mathbf{3}^{\prime}$ & $\begin{array}{c}\text { Temperatura de } \\
\text { anelamento }\left(^{\circ} \mathbf{C}\right)\end{array}$ & PIC \\
\hline UBC-811 & $(\mathrm{GA})_{8} \mathrm{C}$ & 50 & 0,14 \\
UBC-825 & $(\mathrm{AC})_{8} \mathrm{~T}$ & 55 & 0,40 \\
UBC-827 & $(\mathrm{CA})_{8} \mathrm{G}$ & 50 & 0,14 \\
UBC-873 & $(\mathrm{GACA})_{4}$ & 55 & 0,61 \\
UBC-880 & $\mathrm{GGA}(\mathrm{GAG})_{2} \mathrm{AGGAGA}$ & 55 & 0,51 \\
I-810 & $(\mathrm{GA})_{8} \mathrm{~T}$ & 50 & 0,33 \\
I-825 & $(\mathrm{AC})_{8} \mathrm{AT}$ & 50 & 0,23 \\
I-827 & $(\mathrm{AC})_{8} \mathrm{G}$ & 53 & 0,27 \\
$\mathrm{I}-888$ & $\mathrm{BDB}(\mathrm{CA})_{8}$ & 53 & 0,17 \\
\hline
\end{tabular}

As temperaturas de anelamento ideais para os iniciadores apresentaram variações. Todos os marcadores mostraram mais qualidade de amplificação em determinada temperatura, o que indica a importância de testes iniciais de avaliação para garantir a qualidade das informações geradas. Dentre as três temperaturas testadas, a de $50{ }^{\circ} \mathrm{C}$ foi a mais eficiente para $44,4 \%$ dos iniciadores (UBC-811, UBC-827, I-810, I-825), a de $53 \stackrel{\circ}{\circ}$ para $22,2 \%($ I-827, I-888) e a de $55 \stackrel{\circ}{\circ}$ para $33,3 \%$ (UBC-825, UBC-873, UBC-880). Para a identificação da melhor temperatura foi analisada a intensidade dos marcadores gerados, a fim de garantir melhor visualização e precisão dos resultados.

Os iniciadores com maior destaque na avaliação dos genótipos foram o UBC873 e o UBC880, devido ao conteúdo de informação polimórfica superior, gerando maior quantidade de informação e contribuindo mais para a distinção dos indivíduos. Ao estudar o gênero Jatropha, SOONTHORNYATARA et al. (2015) encontraram variação nos valores de PIC de 0,0144 a 0,2050, resultados inferiores aos encontrados no presente estudo, mas que ainda assim foram eficientes na distinção dos indivíduos, mostrando a elevada quantidade de informação gerada.

Os valores de PIC variam de 0 (zero) a 1 (um) e quanto maior o seu valor, maior o conteúdo de polimorfismo (MALONE et al., 2007), assim os iniciadores que menos contribuíram para o agrupamento dos indivíduos foram o UBC-811 e o UBC827.

O agrupamento dos indivíduos de acordo com sua distância genética foi realizado através de um método hierárquico (UPGMA) e de um método de otimização (Tocher). Técnicas estatísticas multivariadas como as análises de agrupamento são capazes de otimizar a coleção de germoplasma e promover o uso racional dos genótipos (REIS et al., 2015).

O dendrograma gerado pelo método UPGMA está representado na Figura 1. Ele foi construído tendo como base a dissimilaridade genética, o que significa que quanto maior o valor de dissimilaridade entre os pares de acesso, valores estes representados na linha horizontal, mais distantes geneticamente são esses acessos. 


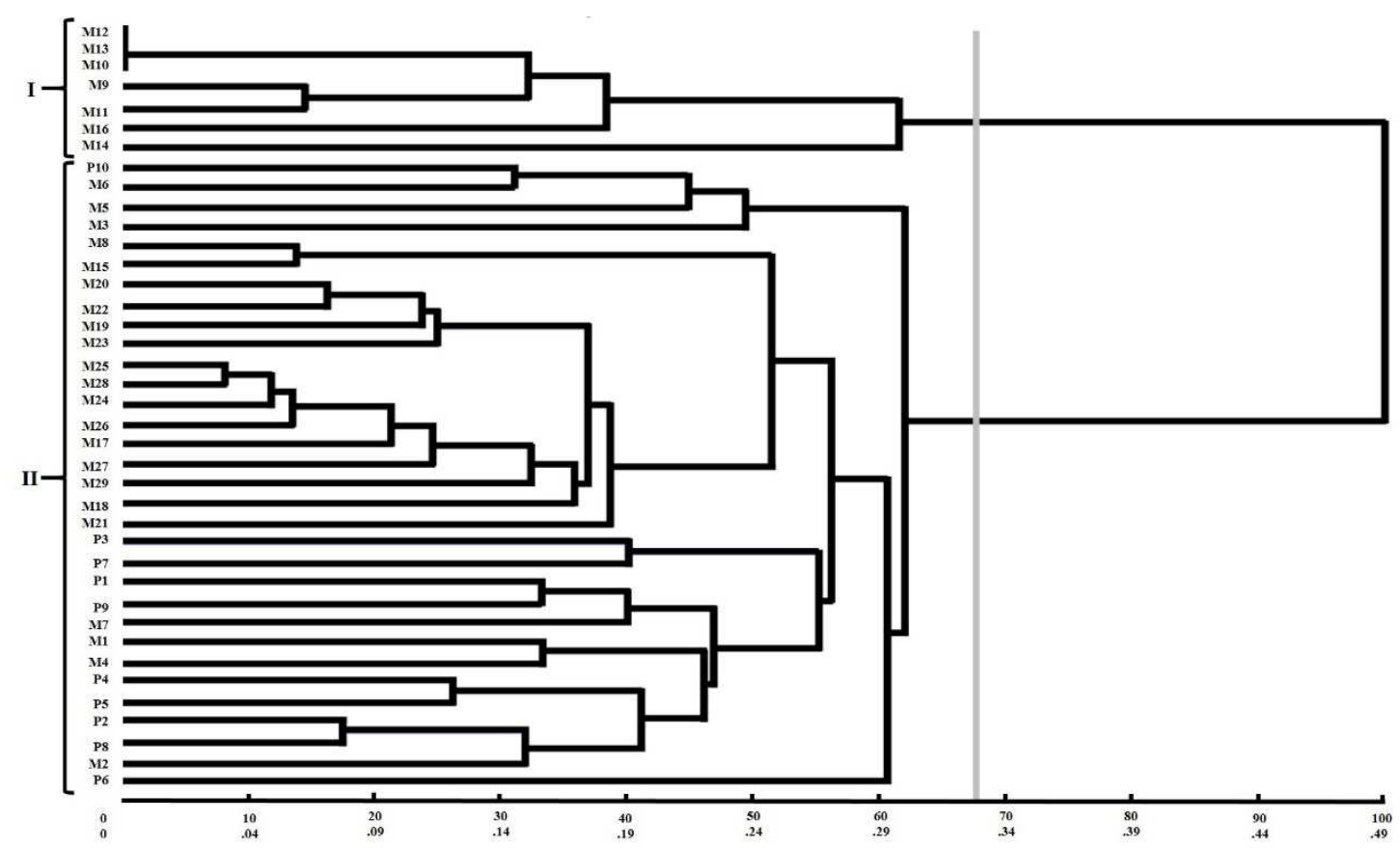

FIGURA 1: Dendrograma de dissimilaridade genética entre genitores e suas famílias, obtido pelo método UPGMA.

Na Figura 1 tem-se destaque para o ponto de corte, gerado pela distância genética média, o qual permitiu a divisão dos acessos em dois grupos, o primeiro com $18 \%$ dos indivíduos e o segundo com $82 \%$. Resultados similares foram obtidos por MAVUSO et al. (2016), que ao avaliarem acessos da espécie cultivados em Taiwan também verificou a formação de apenas 2 grupos pelo método UPGMA, estando a maioria dos acessos (95\%) presentes no primeiro deles.

O grande número de acessos em um mesmo grupo reflete a variabilidade reduzida dos indivíduos, que não é significativa para promover a separação em mais grupos. No entanto, estudos que incluem avaliações morfoagronômicas têm apresentado resultados distintos. Através de variáveis morfológicas PAZETO et al. (2013) obtiveram sete grupos formados a partir do método UPGMA e distância Euclidiana. Ao utilizar marcadores RAPD e SSR e caracteres fenotípicos, ALVES et al. (2013) obtiveram a formação de 18 grupos distintos da espécie em acessos coletados no Brasil pelo método de Tocher. Tais resultados ressaltam a importância das avaliações morfoagronômicas, que associadas às moleculares geram uma separação mais precisa dos grupos e colabora na indicação de recombinações.

A consistência do padrão de agrupamento do dendrograma foi dada pelo coeficiente de correlação cofenética $(r)$, representado na Tabela 2 . $O$ valor de $r$ obtido foi de 0,9114, muito acima do limite mínimo estabelecido por ROHLF (1970), para que o método de agrupamento seja adequado ao resumir a informação do conjunto de dados, que é de 0,7. Também se observam pequenos valores para estresse e distorção, mostrando um pequeno grau de deformação do dendrograma. Assim houve ótima representatividade do gráfico. 
TABELA 2: Coeficiente de correlação cofenética (CCC), estresse e distorção entre as matrizes de distância genética e a resultante do agrupamento dos genitores e suas famílias.

\begin{tabular}{ccc}
\hline Coeficiente de correlação cofenética & Estresse (\%) & Distorção (\%) \\
\hline 0,9114 & 15,4077 & 2,3743 \\
\hline
\end{tabular}

O resultado do agrupamento segundo o método de Tocher foi similar à separação do dendrograma, havendo $93,1 \%$ de sobreposição dos métodos. Apenas dois indivíduos foram agrupados de forma diferente, que são o M16 e o M17. No dendrograma o M16 está no grupo I e o M17 no grupo II, enquanto o método de Tocher os agrupou de forma inversa. Como observado na Figura 1, o primeiro grupo constou de sete acessos e o segundo de 32 e isso ocorreu para as duas metodologias.

Tanto a Ligação Média Entre Grupos (UPGMA) como Tocher utilizam como base de separação dos grupos as medidas de dissimilaridade, no entanto apresentam metodologias distintas, que conduzem a resultados diferentes. $O$ método UPGMA se destaca pelo fornecimento do dendrograma (Figura 1), que facilita a visualização da dissimilaridade entre os acessos, no entanto sua separação de grupos pode ser influenciada pela metodologia selecionada para determinar o ponto de corte. O método de Tocher visa uma partição em grupos de forma a otimizar os critérios avaliados e garantir que indivíduos de grupos diferentes tenham uma maior distância genética que os do mesmo grupo, sendo o mais adequado para a separação dos indivíduos (CRUZ et al., 2011). Para o presente estudo, o número de grupos foi o mesmo para os dois métodos, o que mostra boa representatividade de ambos.

Os resultados dos agrupamentos obtidos pelas duas metodologias podem ser utilizados no melhoramento da espécie de forma a auxiliar no direcionamento do processo de recombinação dos meios-irmãos e indicar os acessos mais divergentes, possibilitando a obtenção de famílias com maior frequência de alelos favoráveis (SILVA et al., 2016).

Nos grupos I gerados pelos dois métodos, observa-se a presença apenas de meios-irmãos, indicando que houve maior distância genética desses acessos com relação aos demais, contribuindo para o aumento da diversidade genética dentro da população. Inicialmente, podem ser indicadas as recombinações entre indivíduos de grupos distintos, mas o ideal seria a associação dos dados de distância genética com um bom desempenho fenotípico, sendo necessários mais estudos de avaliação agronômica das populações (LIMA et al., 2015).

A Tabela 3 mostra as 10 maiores e menores distâncias genéticas entre os acessos, obtidas a partir da matriz de dissimilaridade. Os valores menores e maiores representam, respectivamente, os acessos mais similares e os mais divergentes. 
TABELA 3: Separação dos pares de acessos e famílias com maior e menor similaridade e suas distâncias genéticas.

\begin{tabular}{|c|c|c|}
\hline & Acessos & Distância genética \\
\hline \multirow[t]{10}{*}{ Mais divergentes } & 10 e 23 & 0,629 \\
\hline & 12 e 23 & 0,629 \\
\hline & 13 e 23 & 0,629 \\
\hline & P7 e 10 & 0,615 \\
\hline & P7 e 12 & 0,615 \\
\hline & P7 e 13 & 0,615 \\
\hline & 5 e 11 & 0,615 \\
\hline & 10 e 29 & 0,615 \\
\hline & 11 e 21 & 0,615 \\
\hline & 12 e 29 & 0,615 \\
\hline \multirow[t]{10}{*}{ Mais similares } & 10 e 12 & 0 \\
\hline & 10 e 13 & 0 \\
\hline & 12 e 13 & 0 \\
\hline & 24 e 25 & 0,040 \\
\hline & 25 e 28 & 0,040 \\
\hline & 25 e 26 & 0,040 \\
\hline & 8 e 15 & 0,068 \\
\hline & 9 e 11 & 0,071 \\
\hline & 17 e 24 & 0,076 \\
\hline & 27 e 38 & 0,076 \\
\hline
\end{tabular}

A distância genética entre os acessos variou de zero a 0,629. O valor zero não pode garantir que os acessos estão repetidos, devido ao número reduzido de iniciadores que geraram amplificação, mas significa que todos os locos amplificados pelos iniciadores em estudo se mostraram iguais para esses genótipos.

Os maiores índices de dissimilaridade foram observados entre os acessos $10 \mathrm{e}$ 23, 12 e 23 e 13 e 23. Esses acessos correspondem a famílias de meios-irmãos originados de plantas-mãe distintas e sua distância genética é superior à distância entre seus genitores. Esse aumento de variabilidade é explicado principalmente pela fecundação cruzada que ocorre em plantas alógamas, como o pinhão manso.

Os acessos mais similares são 10 e 12, 10 e 13 e 12 e 13, que também representam famílias de meios-irmãos. Isso mostra que mesmo na polinização cruzada ainda existe a possibilidade de se formarem indivíduos semelhantes. A insuficiente diversidade genética entre os genitores utilizados em cruzamentos pode reduzir a variabilidade de caracteres, especialmente os quantitativos, limitando o progresso genético dessas características, o que ressalta a importância dos estudos de diversidade (BORÉM \& MIRANDA, 2009).

Considerando os genitores e suas famílias como duas populações distintas, foi possível calcular os valores médios de heterozigose para os locus avaliados para as plantas-mãe e para as famílias de meios-irmãos (Tabela 4). O valor de heterozigose das famílias de meios irmãos foi de 0,35 , superior ao valor dos genitores, que foi de 0,18 . Esses dados afirmam o aumento de variabilidade das famílias descendentes de acasalamentos ao acaso, sugerindo que maiores distâncias genéticas possam ser obtidas nas próximas gerações, como já observado por SOARES et al. (2016) em cultivo da espécie in vitro. 
TABELA 4: Heterozigose média dos genitores e famílias de meios-irmãos.

\begin{tabular}{cc}
\hline População & Heterozigose \\
\hline Genitores & 0,18 \\
\hline Meios-Irmãos & 0,35 \\
\hline
\end{tabular}

É importante inserir na população novos genótipos promissores, que possam transferir alelos desejáveis para as próximas gerações. PAZETO et al. (2015) ao estudar três espécies do gênero Jatropha e verificar pequena variabilidade em Jatropha curcas $L$. também indica a possibilidade de cruzamentos interespecíficos com Jatropha pohliana Müll. Arg. e Jatropha gossypiifolia L. A identificação de combinações híbridas com maior heterozigose favorece o desenvolvimento de indivíduos superiores (CRUZ et al., 2012).

$\mathrm{Na}$ busca por parentais para recombinação, é fundamental a confirmação da superioridade genética dos genótipos (TEODORO et al., 2016). O uso de técnicas genético-estatísticas como a divergência genética é fundamental para a seleção das plantas que serão utilizadas nos programas de melhoramento.

\section{CONCLUSÕES}

Houve aumento considerável na distância genética e na heterozigose média das famílias de meios-irmãos com relação aos seus genitores, o que confirma a importância de sua utilização no melhoramento da espécie, tendo em vista sua base genética estreita.

Os acessos mais divergentes, pertencentes a grupos distintos, podem ser utilizados como fonte de variação genética em recombinações, e para sua melhor utilização caracteres morfoagronômicos devem ser avaliados.

\section{REFERÊNCIAS}

ALVES, A. A.; BHERING, L. L.; ROSADO, T. B.; LAVIOLA, B. G.; FORMIGHIERI, E. F.; CRUZ, C. D. Joint analysis of phenotypic and molecular diversity provides new insights on the genetic variability of the Brazilian physic nut germplasm bank. Genetics and molecular biology, v. 36, n. 3, p. 371-381, 2013. Disponível em: <http://www.scielo.br/pdf/gmb/v36n3/2013-020.pdf> doi: 10.1590/S141547572013005000033

BORÉM, A.; MIRANDA, G.V. Melhoramento de Plantas. Viçosa: Editora UFV, 2009. $625 \mathrm{p}$.

CRUZ, C. D. Programa Genes: Diversidade Genética. Viçosa: Editora UFV, 2008. 278p.

CRUZ, C. D.; FERREIRA, F. M.; PESSONI, L. A. Biometria aplicada ao estudo da diversidade genética. Visconde do Rio Branco: Suprema, 2011, 620 p.

CRUZ, C. D.; REGAZZI, A. J.; CARNEIRO, P. C. S. Modelos biométricos aplicados ao melhoramento genético. Viçosa: Editora UFV, 2012. 514p.

DOYLE, J. J. T.; DOYLE, J. L. - Isolation of plant DNA from fresh tissue. Focus, v. 12, p. 13-15, 1990. 
DRUMOND, M. A.; DE OLIVEIRA, A. R.; SIMÕES, W. L.; JUNQUEIRA, N. T. V.; DOS ANJOS, J. B.; LAVIOLA, B. G. Produção e distribuição da biomassa de Jatropha curcas no semiárido brasileiro. CERNE, v. 22, n. 1, p. 35-41, 2016. Disponível em: <http://www.scielo.br/pdf/cerne/v22n1/2317-6342-cerne-22-0100035.pdf> doi: 10.1590/01047760201622012031

GRATIVOL, C.; LIRA-MEDEIROS, C. F.; HEMERLY, A. S.; FERREIRA, P. C. G. High efficiency and reliability of inter simple sequence repeats (ISSR) markers for evaluation of genetic diversity in Brazilian cultivated Jatropha curcas L. accessions. Molecular Biology Reporters, v. 38, n. 7, p. 4245-4256, 2011. Disponível em: <https://link.springer.com/article/10.1007\%2Fs11033-010-0547-7> $10.1007 / \mathrm{s} 11033-010-0547-7$

JUHÁSZ, A. C. P.; RESENDE, M. D.; LAVIOLA, B. G.; COSTA, M. R. Melhoramento genético de Jatropha curcas: considerações e metodologias. In: Pinhão Manso. RESENDE, J. C. F. DE; LONDE, L. N.; NEVES, W. DOS S. (EDS.). Nova Porteirinha (MG): Epamig, p. 89-154, 2013.

LAVIOLA, B. G.; DOS ANJOS, S. D.; JUHÁSZ, A. C. P.; ROCHA, R. B.; DE OLIVEIRA; R. J. P.; ALBRECHT, J. C.; ALVES, A. A.; ROSADO, T. B. Desempenho agronômico e ganho genético pela seleção de pinhão-manso em três regiões do Brasil. Pesquisa Agropecuária Brasileira, v. 49, n. 5, p. 356-363, 2014. Disponível em: <http://www.scielo.br/pdf/pab/v49n5/0100-204X-pab-49-05-0356.pdf> doi: 10.1590/S0100-204X2014000500005

LAVIOLA, B. G.; ROSADO, T. B.; BHERING, L. L.; KOBAYASHI, A. K.; DE RESENDE, M. D. V. Genetic parameters and variability in physic nut accessions during early developmental stages. Pesquisa Agropecuária Brasileira, v. 45, n. 10, p. 1117-1123, 2010. Disponível em: <http://www.scielo.br/scielo.php?script=sci_arttext\&pid=S0100204X2010001000010 > doi: 10.1590/S0100-204X2010001000010

LIMA, E. N.; DE ARAÚJO; M. E. B.; BERTINI; C. H. C DE M.; MOURA, C. F. H. HAWERROTH, M. C. Genetic diversity of clones of acerola assessed by ISSR molecular markers. Comunicata Scientiae, v. 6, n. 2, p. 174-180, 2015. Disponível em: <https://www.comunicatascientiae.com.br/comunicata/article/view/541/316>

MALONE, G.; ZIMMER, P. D.; DE CASTRO, M. A. D. S.; ARIAS, L. N.; MENEGHELLO, G. E.; PESKE, S. T. Caracterização bioquímica e molecular de acessos de arroz vermelho coletados no estado do Rio Grande do Sul. Pesquisa Agropecuária Tropical, v. 37, n. 2, p. 77-85, 2007. Disponível em: <https://www.revistas.ufg.br/pat/article/view/1823/1742>

MARQUES, D. A.; FERRARI, R. A. O Papel das Novas Biotecnologias no Melhoramento Genético do Pinhão Manso. Biológico, v.70, n.2, p. 65-67, 2008. Disponível em: <http://www.biologico.sp.gov.br/docs/bio/v70_2/65-67.pdf>

MAVUSO, C.; WU, Y. P.; CHEN, F. C.; HUANG, B. H.; LIN, S. J. Genetic diversity analysis of Jatropha curcas $L$. accessions cultivated in Taiwan using inter simple 
sequence repeats (ISSR) markers. Agroforestry Systems, v. 90, n. 3, p. 417-431, 2016.

Disponível

em:

<http://download.springer.com/static/pdf/737/art\%253A10.1007\%252Fs10457-015-

9864-

0.pdf?originUrl=http\%3A\%2F\%2Flink.springer.com\%2Farticle\%2F10.1007\%2Fs 1045 7-015-9864-

0\&token2=exp=1491417724 acl=\%2Fstatic\%2Fpdf\%2F737\%2Fart\%25253A10.1007 \%25252Fs10457-015-9864-

0.pdf\%3ForiginUrl\%3Dhttp\%253A\%252F\%252Flink.springer.com\%252Farticle\%252 F10.1007\%252Fs10457-015-9864-

$0^{*} \sim$ hmac $=c 93519$ ea47c1f4a45bcdd0b3c3bf564116be2f10d85ffa676248925936fa1e3 C> doi: $10.1007 / \mathrm{s} 10457-015-9864-0$

MÜLLER, M. D.; BRIGHENTI, A. M.; PACIULLO, D. S. C.; MARTINS, C. E.; DA ROCHA; W. S. D.; DE OLIVEIRA, M. H. S. Produção de plantas de pinhão manso em diferentes espaçamentos e tipos de consórcio. Ciência Rural, v. 45, n. 7, p. 1167-1173, 2015. Disponível em: <http://www.scielo.br/pdf/cr/2015nahead/16784596-cr-0103_8478cr20131624.pdf> doi: 10.1590/0103-8478cr20131624

NUNES, A. J. O.; EXLER, R. B.; NUNES, F. M.; PAULILLO, L. C. M. S. Diagnose visual de deficiências minerais em mudas de pinhão manso (Jatropha curcas L.) em função de diferentes doses de macro e micronutrientes. Energia na Agricultura, v. $31, \quad$ n. $3, \quad$ p. 231-236, 2016. Disponível em: <http://200.145.140.50/index.php/energia/article/view/2139/pdf> doi: 10.17224/EnergAgric.2016v31n3p231-236

PAZETO, M. S. R.; UNÊDA-TREVISOLE, S. H.; CORRÊA, A. A. P.; VIANNA, V. F.; LEITE, D. C.; DI MAURO, A. O. Genetic diversity in Jatropha species from different regions of Brazil based on morphological characters and inters-simple sequence repeat (ISSR) molecular markers. African Journal of Biotechnology, v. 14, n. 25, p. 2066-2079, 2015. Disponível em: <https://www.ajol.info/index.php/ajb/article/view/120502/109965> doi: 10.5897/AJB2014.14368

REIS, M.V.M.; DAMASCENO JÚNIOR, P. C.; CAMPOS, T. DE O.; DIEGUES, I. P.; FREITAS, S. C DE. Variabilidade genética e associação entre caracteres em germoplasma de pinhão-manso (Jatropha curcas L.). Revista Ciência Agronômica, v. $46, \quad$ n. 2 , p. 2412-420, 2015. Disponível em: <http://www.scielo.br/pdf/rca/v46n2/0045-6888-rca-46-02-0412.pdf> doi: $10.5935 / 1806-6690.20150021$

RESENDE, M. D. V. Correções nas expressões do progresso genético com seleção em função da amostragem finita dentro de famílias de populações e implicações no melhoramento florestal. Boletim Pesquisa Florestal, n. 22/23, p. 61-77, 1991. Disponível em: <https://ainfo.cnptia.embrapa.br/digital/bitstream/item/29852/1/resende1.pdf>

ROCHA, R. B.; LAVIOLA, B. G.; DOS ANJOS; S. D., JUHÁZ; A. C. P.; ALBRECHT, J. C.; ROSADO, T. B. Adaptabilidade e estabilidade de progênies de meios-irmãos de pinhão-manso em diferentes regiões do Brasil. Revista Ceres, v. 63, n. 2, p. 174- 
182, 2016. Disponível em: <https://www.embrapa.br/web/mobile/publicacoes//publicacao/1051738/adaptabilidade-e-estabilidade-de-progenies-de-meios-irmaosde-pinhao-manso-em-diferentes-regioes-do-brasil> doi: $10.1590 / 0034-$ 737X201663020008

ROHLF, F. J. Adaptative hierarquical clustering schemes. Systematic Zoology, v.19, n.1, p.58-82, 1970. Disponível em: <https://academic.oup.com/sysbio/articleabstract/19/1/58/1647480/Adaptive-Hierarchical-Clustering-Schemes> doi: 10.1093/sysbio/19.1.58

SILVA, D. F. G.; DE JESUS COELHO, C.; ROMANEK, C.; GARDINGO, J. R.; DA SILVA, A. R.; GRACZYKI, B. L.; OLIVEIRA, E. A. T.; MATIELLO, R. R. Dissimilaridade genética e definição de grupos de recombinação em progênies de meios-irmãos de milho-verde. Bragantia, v. 75, n. 4, p. 401-410, 2016. Disponível em: <http://www.scielo.br/pdf/brag/v75n4/pt_0006-8705-brag-1678-4499343.pdf> doi: $10.1590 / 1678-4499.343$

SILVA, L. M. DA; FELICIO, R.; SILVA, F. D. C. M.; CUSTÓDIO, I. C.; SILVEIRA, P. S. D.; MATOS, F. S. Temperature and maturation stage: its effects on the germination of Jatropha seeds. Journal of Seed Science, n. AHEAD, p. 0-0, 2017. Disponível em: <http://dx.doi.org/10.1590/2317-1545v39n1166552> doi: 10.1590/2317-1545v39n1166552

SOARES, D. M. M.; SATTLER, M. C.; FERREIRA, M. F. S.; PRAÇA-FONTES, M. M. Assessment of genetic stability in three generations of in vitro propagated Jatropha curcas L. plantlets using ISSR markers. Tropical Plant Biology, v. 9, n. 4, p. 229238, 2016. Disponível em: <https://link.springer.com/article/10.1007/s12042-0169171-6> doi: 10.1007/s12042-016-9171-6

SOONTHORNYATARA, S.; SRIPICHITT, P.; KAVEETA, R.; HONGTRAKUL, V. Assessment of genetic diversity of Jatropha curcas L. using AFLP and ISSR markers. Chiang Mai Journal of Science, v. 42, n. 3, p. 614-625, 2015. Disponível em: <http://www.thaiscience.info/journals/Article/CMJS/10972697.pdf>

SPINELLI, V. M.; DIAS, L. A. DOS S.; ROCHA, R. B.; RESENDE, M. D. V. Yield performance of half-sib families of physic nut (Jatropha curcas L.). Crop Breeding and Applied Biotechnology, v. 14, n. 1, p. 49-53, 2014. Disponível em: <http://www.scielo.br/pdf/cbab/v14n1/08.pdf> doi: 10.1590/S198470332014000100008

TEODORO, P. E.; COSTA, R. D.; ROCHA, R. B.; LAVIOLA, B. G. Número mínimo de medições para a avaliação acurada de características agronômicas de pinhão-manso. Pesquisa Agropecuária Brasileira, v. 51, n. 2, p. 112-119, 2016. Disponível em: <http://seer.sct.embrapa.br/index.php/pab/article/view/21727/13210> doi: 10.1590/S0100-204X2016000200003

VIRGENS, I. O.; CASTRO, R. D. D.; LOUREIRO, M. B.; FERNANDEZ, L. G. Revisão: Jatropha curcas L.: aspectos morfofisiológicos e químicos. Brazilian Journal of Food Technology, v. 20, 2017. Disponível em: 
<http://www.scielo.br/pdf/bjtt/v20/1981-6723-bjtt-1981-67233016.pdf>

doi:

10.1590/1981-6723.3016 